\title{
Offset printing results analysis of different based inks in cardboard pack- aging production
}

\author{
Osman Şimşeker \\ Marmara University, Technical Education Faculty, Printing Education Department and School of Applied Sciences, \\ Printing Technologies Department, Göztepe 34722 - İstanbul, Turkey \\ "Corresponding author: e-mail: osmansimseker@marmara.edu.tr
}

\begin{abstract}
The main raw material of paper and cardboard used in packaging is cellulose. Cardboard packages made of cardboard, which can be produced in much different quality and weight, are obtained in numerous shapes and appearances ${ }^{\mathbf{1}, 2}$. Paper and cardboard packaging are among the most economical packaging types. Using less raw materials, more durable but thin, light, economical cardboard is produced ${ }^{2,3}$.

In this study, under equal printing conditions, test prints were made on cardboard substrates (for cardboard packaging) with mineral oil based, vegetable oil (soy oil) based and UV cured inks used for the printing of the same images. After these prints, the properties of mineral oil, vegetable oil and UV ink; the effect on the print results was measured from different ways (Chroma*, Print density, unprinted surface Gloss $75^{\circ}$, Print Gloss $60^{\circ}$ ). At the same time, the visual differences between the print results were determined by the optical imaging (SEM) method and were examined by the elemental analysis method.
\end{abstract}

Keywords: Mineral Oil, Soy Oil, UV Ink, Printability, Cardboard Packaging.

\section{INTRODUCTION}

Pigments are insoluble substances in powder form that give the ink its color. Because they form the visible identity of the ink and have an important place in the total cost, they are the most important next to other raw materials ${ }^{4,5}$.

The term resin is used to describe unclear, solids or liquids with relatively high molecular weight. These substances generally have low boiling points. They are mostly used to improve the hardness, gloss, adhesiveness, flexibility, absorption properties of the ink. Resins have binding properties for pigments and allow them to adhere to the substrate. Ha et al. synthesized natural resins to produce environmentally friendly ink and analyzed their uses in offset printing ink formulations and the properties of the ink such as gloss, discoloration, ${ }^{1,6,7}$.

Solvent gives the pigments and binders the fluidity that printing machines need to gain to be able to print on the printing materials. Usually used to dissolve resins. During the drying of the solvent, it evaporates or absorbs depending on the type of the ink, forming a resin film on the printing material. Pigment particles are dispersed in this film. They can be used in the form of water, solvent and oil ${ }^{1,8}$.

Special additives; auxiliary materials play a role in turning the binder into a paste or a fluid varnish in accordance with the printing method. Examples of additives are wax, lubricants, surface regulators, foam breakers, plasticizers and binding agents. Dryer, thinner etc. added to the ink. are substances ${ }^{9,10}$.

\section{Specification Of Cardboard Substrate}

Different raw materials are used in the production of paper and cardboard that we encounter in all areas of our lives. The main ones are the trunks of trees found in nature, the stems of plants, textile materials called rags and previously used paper and cardboard ${ }^{\mathbf{1 1}}$.

\section{Mineral Oil-Based (Mob) Ink}

Petroleum-based mineral oil-based inks, although effective, are more expensive than vegetable-based soybean oil-based inks and have a more negative impact on the environment. A very high amount of what is known as VOC (Volatile Organic Compounds); They tend to contain volatile organic compounds, including toluene, benzene, and xylene. These compounds can be very harmful to the environment, wildlife and humans. For example, benzene is a common carcinogen ${ }^{13,14,15}$.

\section{Vegetable Oil (Soy Oil) Based (Sob) Ink}

Soybean oil-based ink is made from soybeans as the name suggests. The oil is refined and then mixed with other environmentally friendly compounds such as natural resins and waxes. Soy oil-based ink is an alternative that can be used for printing newspapers and other mass-produced documents, as it can produce such brilliant colors and is significantly more cost-effective than mineral oil-based inks. Soy ink is an auxiliary ingredient in paper recycling because soy ink can be more easily removed from paper than regular ink during the deinking process. Soy ink also contains low levels of VOCs (volatile organic compounds) that help reduce air pollution by minimizing toxic emissions ${ }^{13}, 14,15$.

\section{UV Cured (UV) Ink}

UV inks have been widely used in the printing industry for more than 20 years, and their use is becoming more and more common day by day. In UV inks, the drying or fixing process must be carried out while the ink is applied to the media. In simple terms, the ink is applied to the surface and instantly dried / fixed by

Table 1. Cardboard specifications ${ }^{\mathbf{1 2}}$

\begin{tabular}{|c|c|c|c|c|c|c|c|c|c|c|}
\hline $\begin{array}{l}\text { Caliper } \\
\text { (mils) }\end{array}$ & $\begin{array}{l}\text { Thickness } \\
\text { (microns) }\end{array}$ & $\begin{array}{l}\text { Nominal weight } \\
24 " \times 36 "\end{array}$ & $\begin{array}{l}\text { Cover weight } \\
20 " \times 26 "\end{array}$ & $\begin{array}{c}\text { Grammage } \\
\mathrm{g} / \mathrm{m}^{2}\end{array}$ & $\begin{array}{c}\text { Gloss } 75^{\circ} \\
\text { GU }\end{array}$ & Smoothness & $\begin{array}{c}\text { Brightness } \\
\%\end{array}$ & $L^{*}$ & $a^{*}$ & $b^{*}$ \\
\hline 10 & 254 & 145 & 87 & 236 & 50 & 1.0 & 92 & 95 & 0.7 & -6.3 \\
\hline
\end{tabular}


means of UV lights. In general, UV-cured inks are printed with a volume of about $0.7-1.2 \mathrm{~cm}^{3} / \mathrm{m}^{2}$, whereas printing varnishes are applied in layers of $2-6 \mathrm{~cm}^{3} / \mathrm{m}^{2}$. Prints made with UV ink are completely resistant to water and to a large extent, unlike solvent prints. The biggest disadvantage of UV inks is the need for drying mechanisms with UV lamps during drying and the odor emitted to the environment during drying ${ }^{16,17,18}$.

\section{MATERIALS AND METHODS}

\section{Test Prints and Measurement Charts}

Test prints were made with IGT C1 Offset Test Printing Device on $236 \mathrm{~g} / \mathrm{m}^{2}$ cardboard (Table 1) substrates with $0.20 \mathrm{~g}$ mineral oil-based, vegetable (soy) oil-based and UV offset printing ink under normal printing conditions with a constant $500 \mathrm{~N}$ printing pressure. The prints were made later; Mineral Oil Based and Vegetable Oil Based inks were dried by their own means, UV ink was dried in Aktiprint mini 12-1 UV dryer.

Table 2. Ink Properties

\begin{tabular}{|l|c|c|c|c|c|}
\hline Color & Ink & Light BWS & Alcohol & Solvent Mixture & Alkali \\
\hline Cyan & $43 \mathrm{MX250 \textrm {MOB }}$ & 8 & + & + & + \\
\hline Cyan & $43 \mathrm{MGA5150} \mathrm{SOB}$ & 8 & + & + & + \\
\hline Cyan & $43 \mathrm{UG5000M}$ UV & 8 & + & + & + \\
\hline
\end{tabular}

Then, test prints' density, Chroma* values, unprinted surface gloss and printing gloss measured with X-rite Spectralfotometer and BYK Gloss Meter. At the same time, the visual differences between the print results have been shown by the optical imaging SEM method.
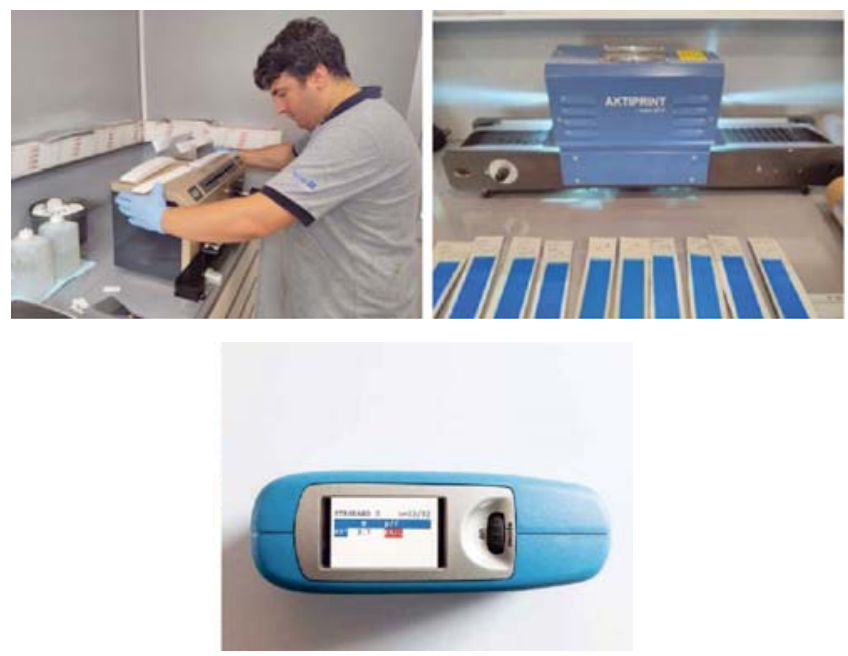

Figure 1. IGT C1 Offset test print machine - UV dryer - Glossmeter ${ }^{19}$

Devices used: IGT C1 Offset Test Machine; X-rite Spectralphotometer; (SEM), ZEISS EVO MA10; BYK Glossmeter (Gloss Meter); EN-ISO 2813; Aktipirint Mini 12-1 UV Dryer; CIE L, a, b Measurement Conditions: Filter: Pol; Paper White: Paper; Density Standard: DIN; Observation Angle: $2^{\circ}$

\section{RESULTS AND DISCUSSIONS:}

\section{Print Chroma}

In Figure 2, Spectral measurements of Mineral Oil Based (MOB) Cyan, Vegetable (Soy) Oil Based (SOB) Cyan and UV (UV) Cyan ink were printed on cardboard substrates and different results were measured in each of

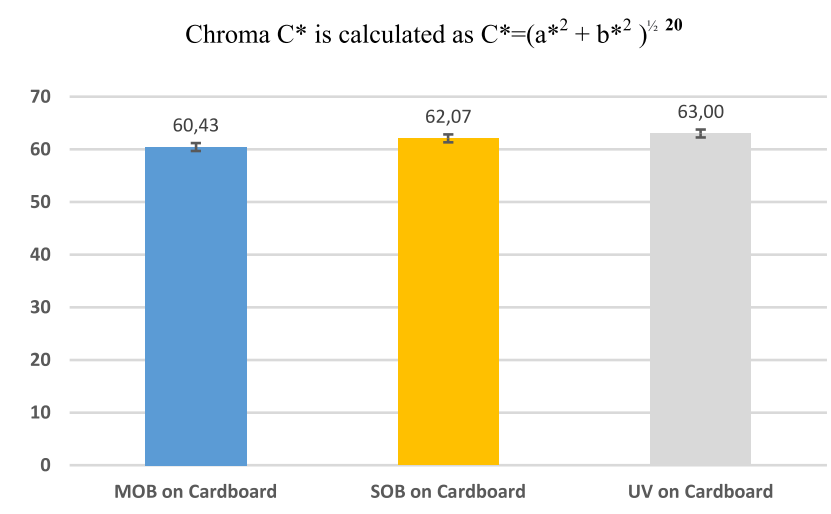

Figure 2. Chroma* values of print results on cardboard

them. In this case, it has been understood that the color values of the printing are different due to the different chemical structures of the ink and the solvent (mineral oil, soy oil, UV ink) difference.

\section{Print Density}

In Figure 3, the Printing density of MOB, SOB and UV Cyan ink were measured and different results were measured in each of them. In these measurements, the lowest density value was measured in MOB ink, the highest ink density value was measured in UV ink, the density of the SOB ink's density value was measured between the other two inks. In this case, it was understood that the solvent difference of the ink and the ink difference affect the ink density values of the printing in the prints made on the cardboard substrates ${ }^{21}$.

Density $=\log 101 / \mathrm{R}$, Where R $=$ Reflectance, Density is a function of the percentage of light reflected. The values below shows the relationship of percent reflectance to Density ${ }^{22}$.

$\begin{array}{lll}\text { \% Reflectance } & & \text { DENSITY } \\ 100 \% & = & 0.0 \mathrm{D} \\ 10 \% & = & 1.0 \mathrm{D} \\ 1 \% & = & 2.0 \mathrm{D} \\ 0.1 \% & = & 3.0 \mathrm{D} \\ 0.01 \% & = & 4.0 \mathrm{D}\end{array}$

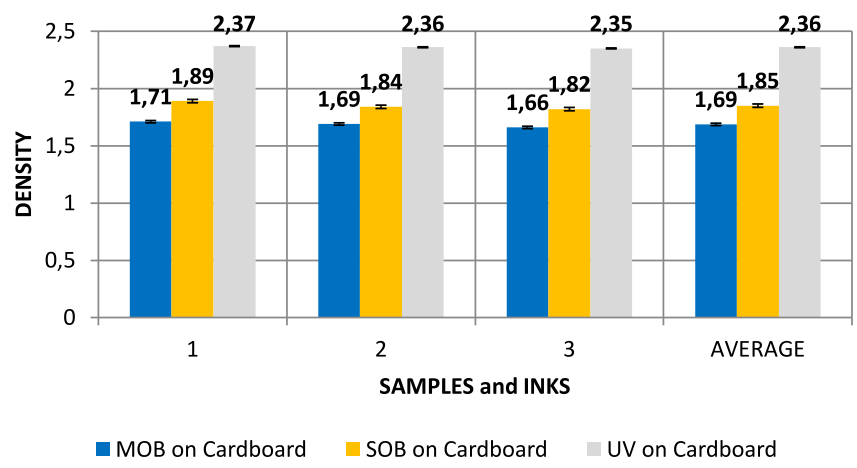

Figure 3. Density values of print results on cardboard

\section{Gloss $75^{\circ}$}

In Figure 4, surface gloss measurements of cardboard substrates samples (3 samples) were made unprinted (Surface Gloss $75^{\circ}$ ) and then these measurements were averaged. The gloss measurement of the unprinted surface was the same in all three samples. 


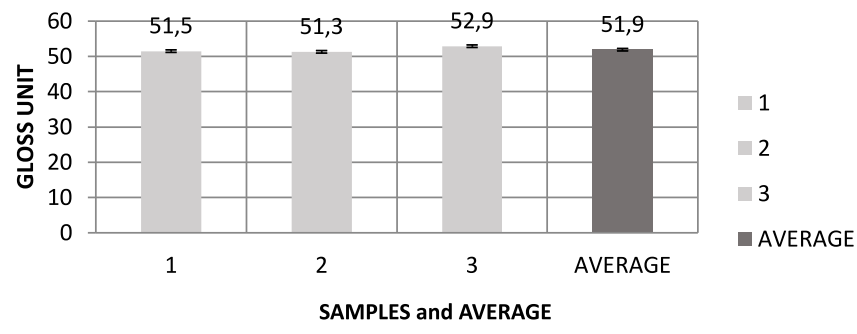

Figure 4. Gloss $75^{\circ}$ values on cardboard

\section{Print Gloss $6^{\circ}$ On Cardboard}

In Figure 5, the samples made on cardboard substrates; The print brightness (Print Gloss $60^{\circ}$ ) measurements of MOB, SOB and UV Cyan ink were made and then the average was calculated. Considering the average print brightness (Print Gloss $60^{\circ}$ ) of three different inks examined, different results were measured in all three. In these measurements, the lowest Print Brightness value was measured in MOB ink, the highest Print Brightness value was measured in SOB ink, the Print Brightness value of the UV ink was the between of the brightness value of the other two inks. In this case, it was understood that the solvent difference of the ink and the ink difference affect and change the printing brightness values in the prints made on the cardboard substrate and this change is not similar to the difference in the ink density values.

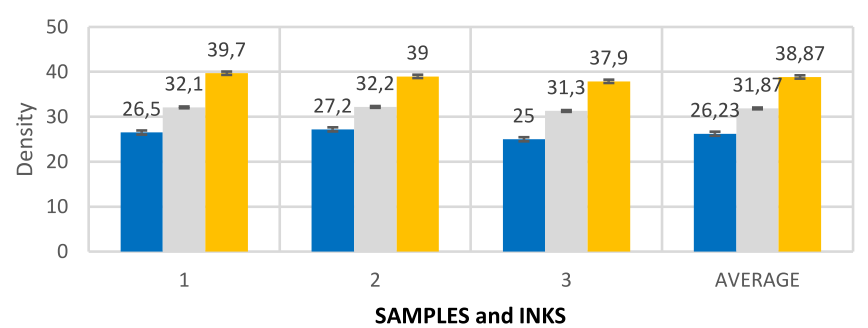

Figure 5. Print Gloss $60^{\circ}$ values of print results on cardboard

\section{Printed Surface Images}

Figure 6 shows the surface image of the unprinted cardboard surface and MOB ink surface. These images show that the unprinted cardboard surface is smoother than the MOB ink printed surface.
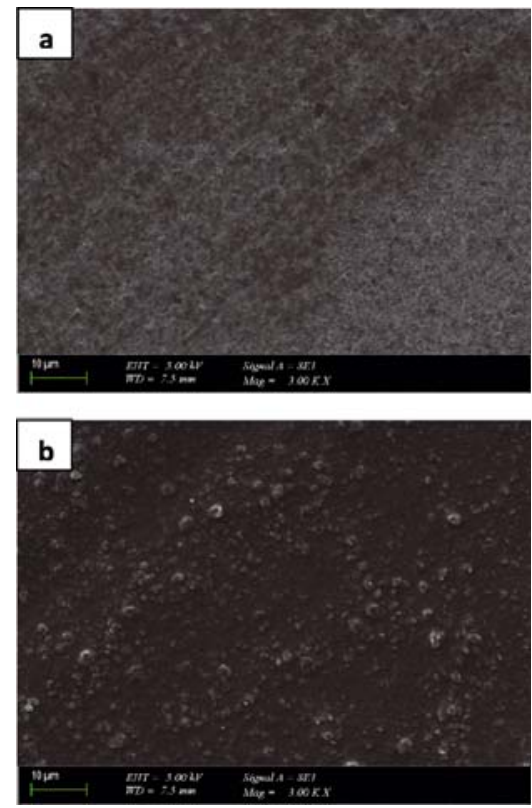

Figure 6. A combination of unprinted cardboard (a) and cardboard on which MOB ink (b) is printed
Figure 7 shows the surface image of unprinted cardboard and SOB ink. These images show that the unprinted cardboard surface is smoother than the SOB ink printed surface.
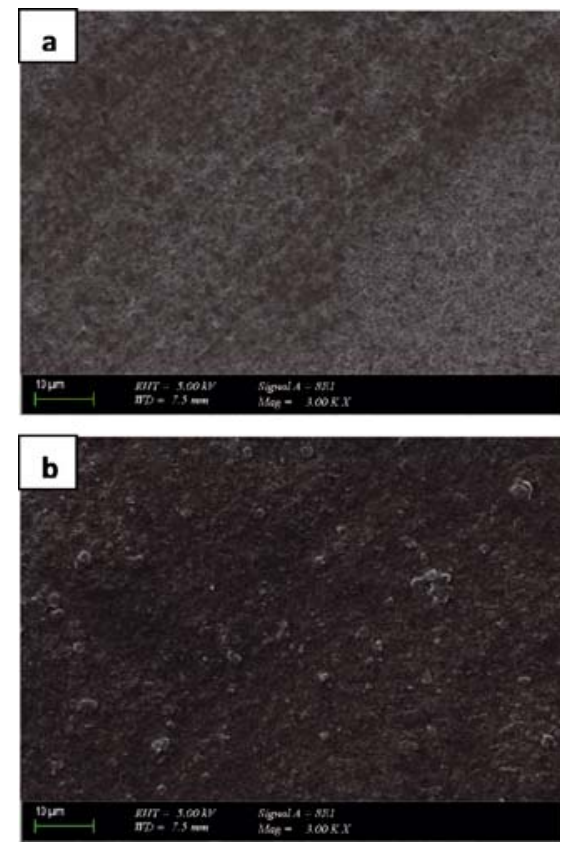

Figure 7. A combination of unprinted cardboard (a) and cardboard on which SOB ink (b) is printed

Figure 8 shows the surface image of unprinted cardboard and UV ink. These images show that the smoothness of the unprinted cardboard surface and the UV ink printed surface are similar.
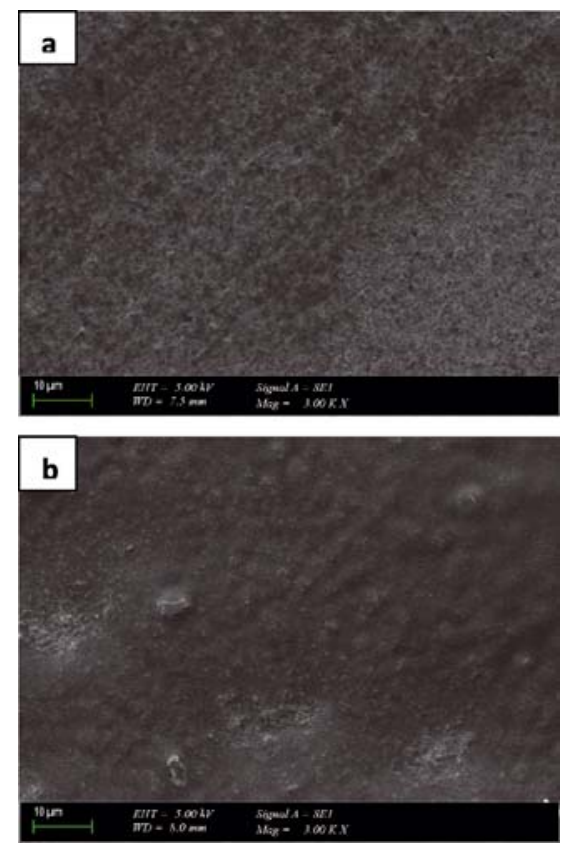

Figure 8. A combination of unprinted cardboard (a) and cardboard on which UV ink (b) is printed

Figure 9 shows the surface image of MOB ink, SOB ink and UV ink surface. These images are in the order of the smoothness of the ink printed surfaces; It shows that it is UV ink, SOB ink and MOB ink. 

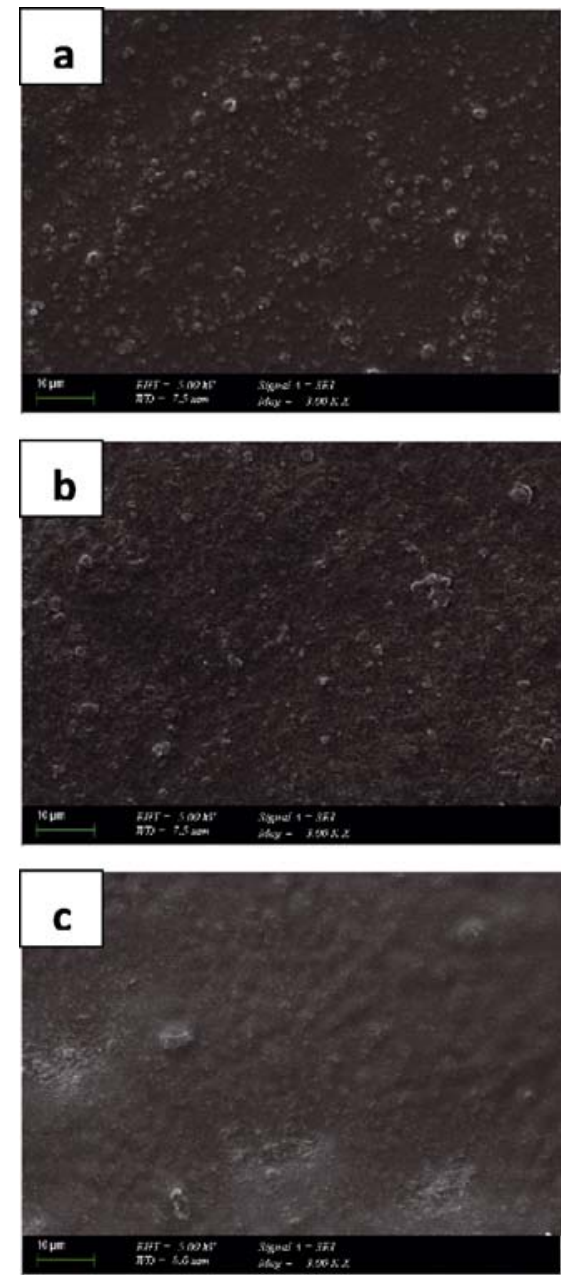

Figure 9. Views of MOB (a), SOB (b) and UV ink (c) printed cardboards

\section{SURFACE ELEMENT ANALYSES}

Figure 10 presented the surface element analysis image of the unprinted cardboard and the measured $\mathrm{C}$ and $\mathrm{O}$ element percentages in the table above and Table 3.

Figure 11 shows the surface element analysis image of MOB ink, SOB ink and UV ink and the measured $\mathrm{C}$ and $\mathrm{O}$ element percentages in the table above and Table 3.

In Figure 12, carbon and oxygen elements obtained as a result of surface element analysis can be seen. Different amounts of carbon and oxygen were determined in

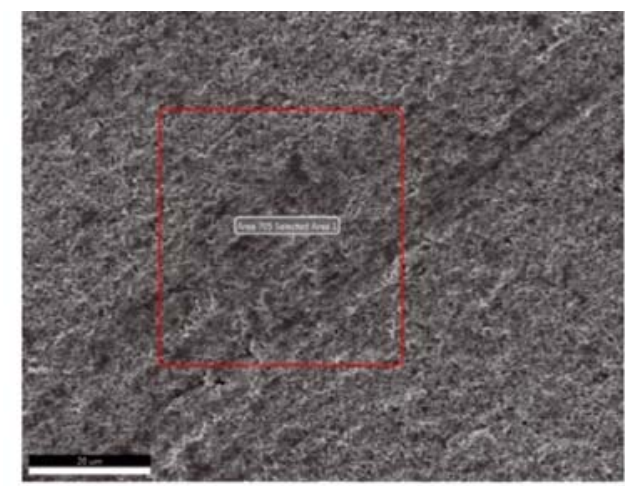

Smart Quant Results

\begin{tabular}{|c|c|c|c|}
\hline Element & Weight \% & Atomic \% & Error \% \\
\hline \multicolumn{4}{|c|}{ New Project | New Sample | Area 705 | Selected Area 1} \\
\hline $\mathrm{CK}$ & 27.58 & 33.66 & 10.87 \\
\hline OK & 72.42 & 66.34 & 8.9 \\
\hline
\end{tabular}

Figure 10. Unprinted Cardboard Surface Element Analysis

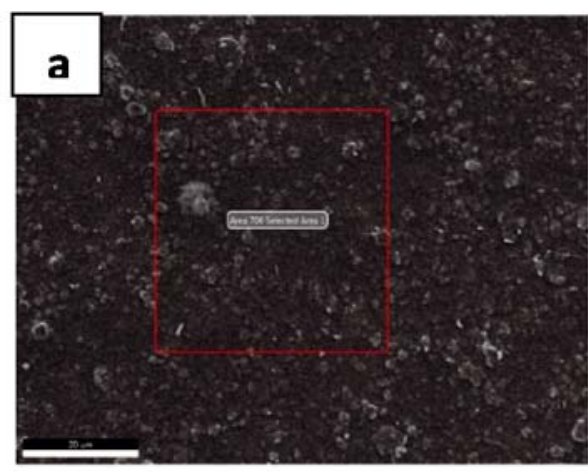

Smart Quant Results
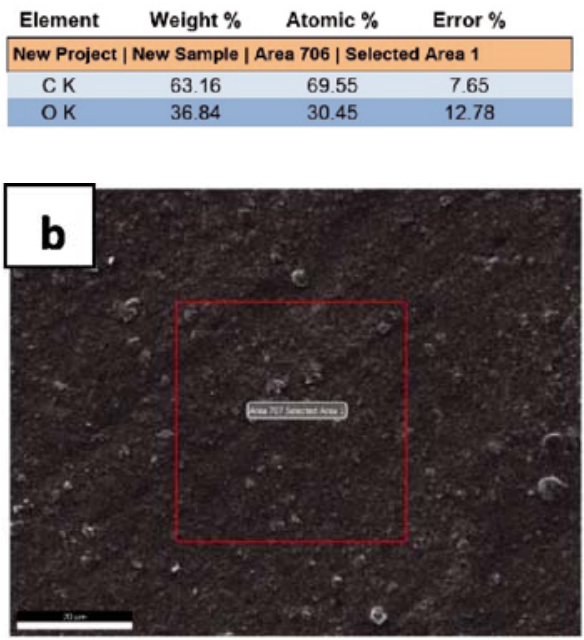

Smart Quant Results
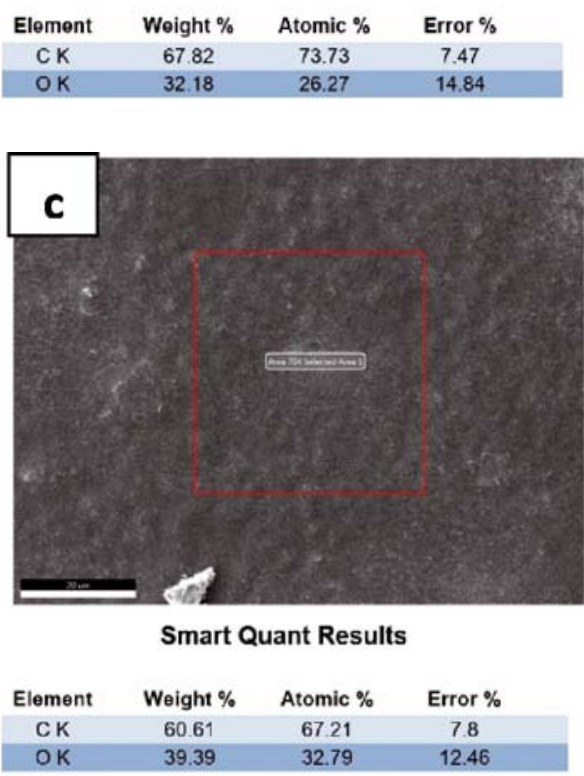

Figure 11. Unprinted Cardboard's (a), MOB ink's (b), SOB ink's (c) and UV ink's (d) surface element analysis graphics

Table 3. Unprinted Cardboard, MOB, SOB and UV ink on Cardboard Surfaces' "Surface Elemental Analysis"

\begin{tabular}{|c|c|c|c|c|}
\hline \multicolumn{5}{|c|}{ Surface element Analysis } \\
\hline & Element & Weight\% & Atomic\% & Error\% \\
\hline \multirow{2}{*}{ Cardoboard } & CK & 27.58 & 33.66 & 10.87 \\
\cline { 2 - 5 } & OK & 72.42 & 66.34 & 8.9 \\
\hline \multirow{2}{*}{ MOB } & CK & 63.16 & 69.55 & 7.65 \\
\cline { 2 - 5 } & OK & 36.84 & 30.45 & 12.78 \\
\hline \multirow{2}{*}{ SOB } & CK & 67.82 & 73.73 & 7.47 \\
\cline { 2 - 5 } & OK & 32.18 & 26.27 & 14.84 \\
\hline \multirow{2}{*}{ UV } & CK & 60.61 & 67.21 & 7.8 \\
\cline { 2 - 5 } & OK & 39.39 & 32.79 & 12.46 \\
\hline
\end{tabular}



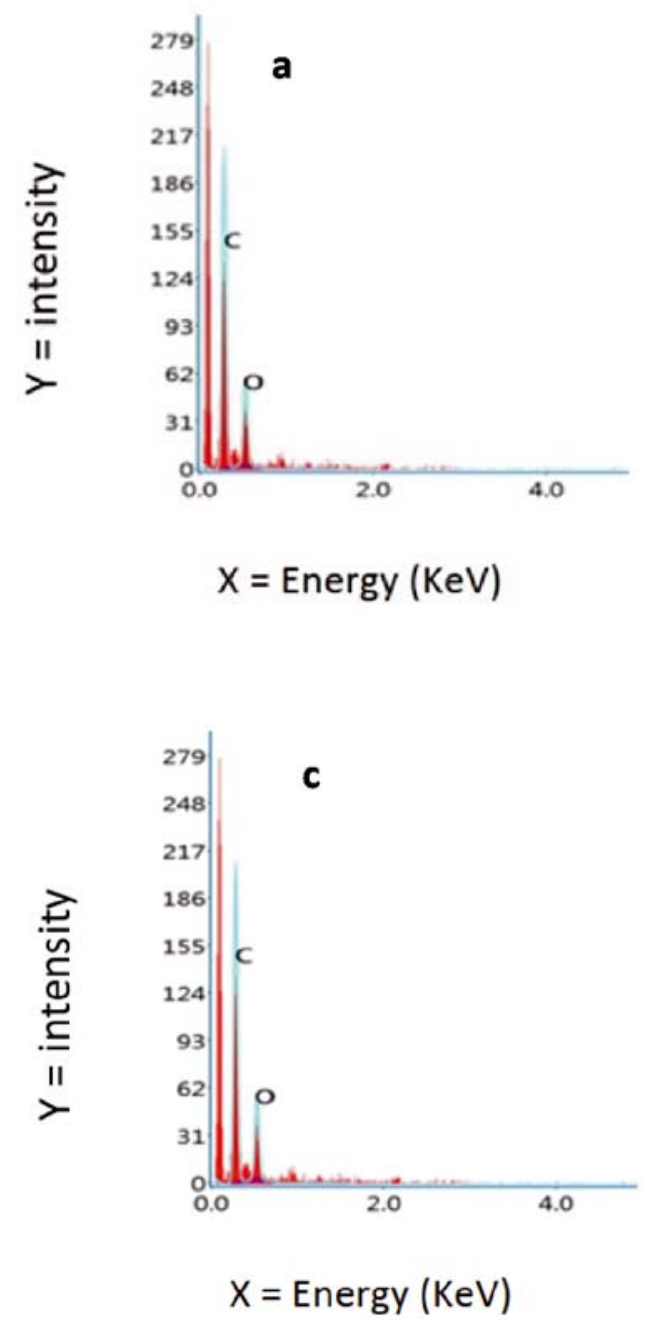
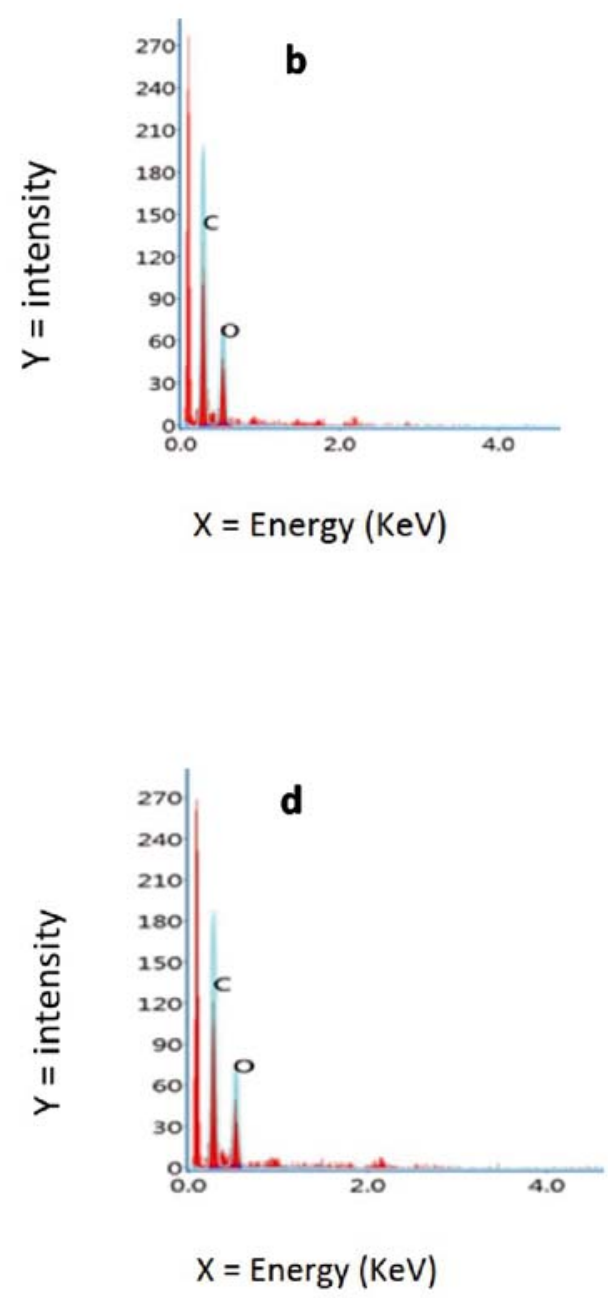

Figure 12. Unprinted Cardboard's, MOB ink's, SOB ink's and UV ink's surface element analysis graphics

surface element analysis. The carbon content is highest in unprinted cardboard and SOB, followed by MOB, least in UV ink. The amount of oxygen in all inks is close to each other.

\section{CONCLUSIONS:}

In the prints made on cardboard substrates, it has been understood that the difference in solvent (mineral oil, soy oil) of the ink and the color values of the printing are different due to the different chemical structures of the inks (Fig. 2). When the results are examined; it has been understood that the color values (Chroma* values) of the printing are different due to the different chemical structures of the ink and the solvent difference.

In the prints made on cardboard substrates, it has been understood that the solvent difference and ink difference of the ink affects the ink density values of the printing and come out differently. In these measurements, the lowest density value was measured in MOB ink, the highest ink density value was measured in UV ink, the density of the SOB ink was between the density value of the other two inks (Fig. 3). UV ink can be preferred due to its high ink density advantage.

When the surface gloss (gloss $75^{\circ}$ ) of the unprinted cardboard was examined, it was seen that the measurements were close to each other and within the standards (Fig. 4).
In the prints made on cardboard printing material, it has been understood that the solvent difference and ink difference of the ink affect and change the Print Gloss (Print Gloss $60^{\circ}$ ) values, and this change is not similar to the difference in ink density values. In the measurements made, the lowest Print Gloss value was measured in MOB ink, the highest Print Gloss value was measured in SOB ink, the Print Gloss value of UV ink was between the gloss value of the other two inks (Fig. 5). SOB ink can be preferred due to its high printing gloss advantage.

In the visual inspection of the printed surface images; It has been visually determined that the surface smoothness is in the best UV ink, the roughest MOB ink, and the surface smoothness of the print made with SOB ink is between the other two inks (Fig. 9). UV ink can be preferred due to the advantage of surface smoothness.

Different amounts of Carbon and Oxygen were determined in surface element analysis. The Carbon content is in the highest SOB, then in the MOB, in the least UV ink. The amount of Oxygen is close to each other in all inks. As a result, when the Carbon content is examined, it can be said that the SOB ink contains the highest amount of organic compounds (Figure 12).

This study shows the differences of three different inks used in offset printing for the cardboard packaging industry in terms of human health, environmental health, Chroma, Print Gloss Value, Surface smoothness, Surface 
element analysis. And the study includes theoretical and practical information on the most important criteria of the cardboard packaging industry. In the results of the study; SOB ink has the highest Print Gloss Value and the least harmful to environmental and human health.

\section{LITERATURE CITED}

1. Şimşeker, O. (2006). "Fundamentals of Printing Education" Marmara University Technical Education Faculty, Department of Printing Education, Lecture Notes, Istanbul, pp. 23-34.

2. https://ambalaj.org.tr/en/environment-paper-and-cardboard-packaging (Date of Access: 30.01.2021 dd.mm.yy).

3. Şimşeker, O. (2019). "Flexible Packaging and Label Production" Lecture Notes, Marmara University, School of Applied Sciences, Department of Printing Technologies, Istanbul, pp. 18-19.

4. Pfaff, G. (2008) "Special Effect Pigments", European Coating Tech Files, Hannower Germany, Vincentz Network, ISBN: 978-3-86630-905-0.

5. Maile J.F. , Pfaff G. and Reynders P. (2005). "Effect Pigments-Past, Present and Future", Progress in Organic Coatings 54, Germany, 150-163.

6. Solomon, D.H. (1967). "The Chemistry of Organic Film Formers", John Wiley \& Sons,New York, 34.

7. Ha, Y.B., Jin, M.Y., Oh, S.S. \& Ryu, D.H., (2012). Synthesis of an environmentally friendly phenol-freeresin or printing ink, Bulletin of The Korean Chemical Society, 33, 3413-3416. DOI: $0.5012 /$ bkcs.2012.33.10.3413.

8. Kipphan, H. (2000), Handbuch der Printmedien, Springer Verlag, Heidelberg, 139.

9. Thompson, B. (2004). Printing Materials Science and Technology. 2nd Edition, DK, 371-380.

10. Bieleman, J., (2000). "Additives for Coatings", Wiley-VCH Verlag, Weinheim (ISBN 3-527-29785-5), 372.

11. Şimşeker, O. (2017). "Graphic Production Techniques" Lecture Notes, Marmara University, Faculty of Fine Arts, Graphic Department, Istanbul, pp. 13.
12. https://cdn-s3.sappi.com/s3fs public/091019_ Web_v6.pdf (Date of Access: 28.01.2020 dd.mm.yy).

13. https://www.psprint.com/resources/soy-based-inks-vs-petroleum-based-inks/ (Date of Access: 28.01.2020 dd.mm.yy).

14. Robert, T. (2014). Green ink in all colors-printing ink from renewable resources, Progress in Organic Coatings, 78 pp 287-292. DOI: 10.1016/j.porgcoat.2014.08.007.

15. Aydemir, C., Yenidoğan, S., Karademir, A. \& Kandırmaz, E.A. (2018). The examination of vegetable and mineral oil based inks' effects on print quality: green printing effects with different oils. J. Appl. Biomat. Function. Mater. 1-7 pp. 137-143. DOI: 0.1177/2280800018764761.

16. Gerrietts, M., Cooke, L. \& Wood, M. (1993). "Soy! It's no ordinary bean." Agricultural Research, November 1, https:// www.thefreelibrary.com/Soy! + It $\% 27 \mathrm{~s}+$ no + ordinary + bean.-a014673309 (Date of Access: 20.01.2021 dd.mm.yy)

17. Gabriele, M., Olesya, D., Katja, H., Tom, S., Beatrix, G., Carolin, S. \& Carsten, S. (2014). In-line monitoring of the conversion in UVcured printed layers by NIR spectroscopy in an offset printing press. Progress in Organic Coatings Volume 77, Issue 3, pp. 719-724. DOI: 10.1016/j.porgcoat.2013.12.012.

18. http://www.olbiaprinter.com/konu/11-uv-murekkep-nedir. html (Date of Access: 25.01.2021 dd.mm.yy).

19. https://www.byk-instruments.com/en/Appearance/c/1978 (Date of Access: 17.01.2021 dd.mm.yy).

20. https:/journals.ashs.org/hortsci/view/journals/hortsci/27/12/ article-p1254.pdf (Date of Access: 30.01.2021 dd.mm.yy).

21. Dharavath, H.N. \& Hahn, K. (2009). Green Printing: Colorimetric and Densitometric Analysis of Solvent-based and Vegetable Oil-based Inks of Multicolor Offset Printing. J. Technol. Stud. 35(2), pp. 36-46.

22. https://xritephoto.com/documents/literature/en/L7 093_Understand_Dens_en.pdf (Date of Access: 29.03.2021 dd.mm.yy).

23. Ström, G. \& Karathanasis M. (2008)"Relationship between ink film topography and print gloss in offset prints on coated surfaces" De Gruyter Published online: July 19, 2018, pp. 156-163. DOI: https://doi.org/10.3183/npprj, 